The effects of length of service and ethical ideologies on moral development and behavioral intentions: a study among Brazilian public sector tax auditors

\author{
Ricardo Malagueño \\ r.malagueno@uea.ac.uk \\ University of East Anglia \\ Norwich Business School \\ Sudarshan Pillalamarri \\ sudarshan.pillalamarri@dmu.ac.uk \\ De Montfort University \\ Leicester Castle Business School \\ Amaury José Rezende \\ amauryj@usp.br \\ University of Sao Paulo \\ FEA - RP \\ Marcelo Botelho da Costa Moraes \\ mbotelho@usp.br \\ University of Sao Paulo \\ FEA - RP
}

Acknowledgements: We would like to thank Dr Robert Jenkins, Dr Stephen B. Salter, Peter Russell and participants at the Norwich Business School Accounting Research Seminar Series for helpful comments. This research was made possible by funding from Eastern Academic Research Consortium (Eastern ARC). 


\title{
The effects of length of service and ethical ideologies on moral development and behavioral intentions: a study among Brazilian public sector tax auditors
}

\begin{abstract}
Purpose- This research examines the effects of length of service and ethical ideologies on cognitive moral development and ethical behavioral intentions among public sector tax auditors in Brazil.
\end{abstract}

Design/methodology/approach- Our research data was collected via survey questionnaires from a sample of 625 auditors who work for the Brazilian tax authority. Participants voluntarily complete an on-line instrument which included three scenarios with context-specific moral dilemmas, questions about the specific scenarios, and an ethics position questionnaire. Multinomial logistic and ordinary least square regressions were used to analyze the data.

Findings- Our findings reveal that a) public sector tax auditors with shorter length of service are more likely to be at higher stages of moral development, b) relativistic ideology among public sector auditors is positively associated with more lenient ethical behavioral intention, c) idealistic ideology among public sector auditors is positively associated with stricter ethical behavioral intention, d) public sector auditors classified as absolutists are stricter in their ethical behavioral intentions, e) public sector auditors classified as absolutists with length of service between 5 to 15 years are more likely to be at higher stages of moral development when compared to public sector tax auditors with longer length of service.

Originality/value- To the best of our knowledge, our study is one of the first studies that attempts to understand the effects of length of service and ethical ideology on cognitive moral development and ethical behavioral intention among public sector auditors. Additionally, it examines these issues in the context Latin America.

Keywords: auditors, public sector, ethics, cognitive moral development, ethical ideologies, Brazil 


\section{Introduction}

For many years, Brazil has been in the world spotlight due to corruption scandals that have affected the public and private spheres of its society (Bologna and Ross, 2015). For some researchers, this reflects a culture of corruption that is embedded in Brazilian society (Fisher et al., 2014). The consequences of this unethical and fraudulent conduct, which is well spread in the country, include financial fraud and tax evasion. For instance, it is estimated that tax evasion in Brazil represents $10 \%$ of the country's gross domestic product (SINPROFAZ, 2015). Although, for many years, different Brazilian governments have fought corruption (Lieberman, 2001), efforts have not had the expected effects, and the problem is far from being under control (Afonso et al., 2013). ${ }^{1}$ While part of this problem can be attributed to government structural inefficiencies, evidence shows that a great extent of the problem is due to the judgment of public servants in accounting and auditing positions (OECD, 2011). Prior studies have suggested that for organizational structures to be adequately developed, one must understand the factors that both motivate and pressure their employees to behave in a certain manner (Curtis et al., 2012). This study tries to address some of these factors by examining the moral development and ethical behavior of Brazilian public sector auditors working for the tax administration (hereafter public sector auditors) through the lens of socialization.

Extant literature on both ethical reasoning and socialization concludes that experience has a significant impact on an individual's level of moral development (Ponemon, 1992; Sierra Molina and Orta Perez, 2005). Drawing on the assumption that a longer length of service allows for more socialization (Tuggle et al., 2010), which results from the greater number of opportunities for organizational participants to interact and acquire the values, knowledge, and expected behavior required by the different organizational contexts (Kjeldsen and Jacobsen, 2012), our primary research question looks to examine the effects of length of service on the antecedents of ethical behavior. ${ }^{2}$ More specifically, our study examines the effects of length of service on cognitive moral development (CMD) (Kohlberg, 1969) and ethical behavioral intentions (Curtis et al., 2017) among public sector auditors in Brazil. To obtain a broader understanding of these relationships, we also examine associations between ethical ideologies and CMD, as well

\footnotetext{
${ }^{1}$ The Corruption Perceptions Index (CPI) prepared by Transparency International (TI) ranks Brazil at $96^{\text {th }}$ with 37 points in 2017 (Transparency International, 2017). In contrast, the country that is perceived as least corrupt on this index was New Zealand, which scored 89 points. The perception of corruption in Brazil seems to be worsening over the years, as Brazil was ranked $69^{\text {th }}$ and scored 43 points on the CPI in 2012.

${ }^{2}$ Within the ethical behavior literature, the terms ethics and morality are often used interchangeably (Doyle et al., 2014).
} 
as ethical ideologies and ethical behavioral intention. Ethical ideology represents the system of ethics used for decision making. This system has long been recognized as a guide for the judgement and behavior of individuals when applied to ethical problems (McFerran et al., 2010).

Prior findings on the effects of socialization on auditors' moral development and ethical behavioral intention were mostly obtained from studies conducted in developed economies characterized by high levels of governmental transparency, public accountability, and law compliance (Bailey et al., 2010; Uysal, 2010). The findings of these studies cannot be easily translated to developing economies. Public administration literature shows that moral reasoning differs considerably across public sector employees in different jurisdictions (Stewart et al., 2002). While the literature suggests that socialization among public sector employees in developed Western economies would lead to higher levels of moral development as individuals become exposed and learn public service-related virtues and norms (Pandey et al., 2016, Stensöta 2010), it is unclear whether similar behavior could be found in developing economies.

This study contributes to the accounting, ethics and public sector literature. First, it provides quantitative evidence of the effects of socialization and ethical ideologies on moral development and ethical intentions among public sector auditors. This contribution adds to the limited literature on CMD, ethical ideologies and moral behavioral intentions in the public sector by presenting those issues within the particular context of public sector tax administration in Brazil. Jones et al. (2003) state that it is difficult to observe individuals acting ethically, and this blurs the line between intention to act ethically and acting ethically in reality. High ethical development in individuals may not be the only factor influencing an individual's intention to act ethically; certain job-related pressures and aspects also play an important role in ethical intentions (Jenkins et al., 2008). Although there have been previous studies that examined the CMD of tax practitioners (Frecknall-Hughes et al., 2017), to the best of our knowledge, our study is one of the first that attempts to understand the effects of length of service on CMD and ethical intention among public sector auditors. Additionally, we believe it to be the first study to examine such issues in Latin America. Second, this study highlights a few of the idiosyncrasies within the professional culture and context of Brazilian public sector auditors. Through our study and the use of three moral dilemma cases, we aim to capture the differences in moral development and ethical behavioral intention. We argue that the setting in our study is particularly useful for a better appreciation of the conditions leading to ethical decision 
making. Prior research suggests that the nature of the moral dilemma, whether remote or familiar, has a direct effect on the level of moral reasoning (Doyle et al., 2013). Hence, it is likely that responses reflecting the level of reasoning used in resolving moral dilemmas are better observed in contexts where complex and intense moral dilemmas are part of professionals' daily judgements (Thorne, 2000; Fleming et al., 2009). Finally, this research highlights the need for the public sector, in countries such as Brazil where tax evasion is rampant, to be pro-active in dealing with ethical issues and adopt an early warning system through the constant training of public servants in accounting and auditing positions who are susceptible to making poor ethical judgements. Hence, the results of this study could guide public policy regarding the training of Brazilian tax authority.

The remainder of this article is divided into six sections. In the next section, we provide the theoretical background of our study. In the third section, we review the potential relationships among the length of service, CMD, ethical ideologies and ethical behavioral intention and formulate testable hypotheses. The subsequent sections present the data and methodology and results. Finally, we discuss and conclude the research paper.

\section{Theoretical background}

Next we present a review of the relevant literature. Section 2.1 defines socialization and reviews studies that have attempted to explain auditors' moral reasoning via socialization. Section 2.2 describes the different classifications of ethical ideologies, which have been considered relevant in guiding individuals' ethical behavior. Section 2.3 covers the moral development literature, its definition, development stages and the antecedents that can influence such stages. Finally, section 2.4 reviews literature on the ethical behavioral intention and provides an overview of the Rest's Model of Ethical Action (Rest, 1986).

\subsection{Socialization and moral reasoning}

Socialization refers to how organizational members modify and create a value system by acquiring new information and adapting to the context over time (Chen, 2012). Studies have attempted to explain auditors' moral reasoning ${ }^{3}$ and the effects on ethical behavior by relying on selection-socialization (see Craft (2013), Bailey et al. (2010) and Uysal

\footnotetext{
${ }^{3}$ Moral reasoning refers to the individual cognitive process that occurs when attempting to determine what is morally right and wrong.
} 
(2010), for comprehensive literature reviews). The assumption exists that organizations attract and assimilate professionals who possess certain attributes that are congruent with the characteristics of the organizations (or those of their top management teams) (Ponemon, 1992). Studies on private accounting firms revealed that managers and partners tend to possess lower and more homogeneous levels of moral reasoning (Ponemon, 1992; Abdolmohammadi and Ariail, 2009), therefore suggesting that audit firms promote to higher positions individuals who are at lower stages of moral development (Ponemon, 1990).

The literature in the public sector recognizes that public sector employees present higher levels of moral reasoning than do private sector professionals (Choi, 2006; Perry et al., 2010). Studies among public servants reveal that a fit between the willingness to help others and making a contribution to society attracts individuals into the public sector and influences them once they are employed (Buelens and Van den Broeck, 2007; Vandenabeele, 2008). In this context, socialization is understood as an important mechanism for public organizations to transmit and embed both a "public institutional logic" and public service-related virtues and norms into public sector employees. Public servants with longer lengths of service would have had more exposure to such social values and consequently would have higher moral reasoning (Kjeldsen and Jacobsen, 2012).

Traditionally, Brazil is a collectivistic society. In such societies, employees exhibit an external locus of control. External factors such as positive relationships with superiors tend to impact behavior (Beekun et al., 2003; Ferreira et al., 2012). Ever since the turn of the century, academics have noted rising levels of corruption in public servants (Maesschalck, 2004). Although our study is not an indictment of the prevalent levels of corruption among tax auditors in Brazil, keeping in mind the preceding arguments on socialization and corruption, we aim to examine the impact of socialization on the ethical decision making abilities of Brazilian public sector auditors.

\subsection{Ethical ideologies}

Ethical ideology represents an individual's system of ethics that guides their decisions and behaviors when applied to ethical problems. Forsyth (1980) describes an individual's ethical ideology along two dimensions, namely, relativism and idealism. These dimensions are defined as follows:

1. Relativism refers to the extent to which individuals reject universal moral rules. 
2. Idealism refers to the extent to which individuals believe good consequences can always be obtained.

Based on the inclination of individuals towards the dimensions of relativism and idealism, the following four possible categories were proposed (see Figure 1):

a) Situationists reject moral rules and base moral choices on the belief that there is a best possible outcome in a given situation.

b) Absolutists accept moral rules and base moral choices on the belief that the best possible outcome can always be achieved.

c) Subjectivists reject moral rules and base moral choices on personal values and perspectives.

d) Exceptionists accept moral rules and base decisions on the pragmatic belief that there are exceptions to the rules.

\section{[Insert Figure 1 about here]}

Previous literature suggests that different ethical ideologies influence the likelihood of individuals to recognize a moral issue (Marques and Azevedo-Pereira, 2009); consequently, it was proposed that there is a relationship between ethical ideologies and CMD (Ishida, 2006).

\subsection{Moral development}

Moral development is the process by which individuals adopt principles and values that change their moral reasoning. Moral development theory (Kohlberg, 1969) aims to explain the cognitive framework underlining decision making in the context of moral dilemmas. It does not aim to identify the correctness of decisions; rather, it attempts to understand the cognitive reasoning supporting individual decisions. A seminal work on CMD (Rest, 1979) postulates that moral development occurs in six stages in an upward progression from the lower stages of pre-conventional self-interest to the middle stages of law abidance and conformity and then to the higher stages of adherence to universal principles of justice (Frecknall-Hughes et al., 2017). The pre-conventional level represents stages one and two of moral development. At this level, individuals are expected to follow a morality of obedience; hence, individuals do what they are told to do in exchange for no punishment or reward. The conventional level represents stages three and four of moral development. At this level, morality is understood as an 
interpersonal concordance with expectations; hence, individuals do what they think is "right" to conform to the expectations of family, friends or society. The post-conventional level represents stages five and six. At this level, individuals understand what is "right" regardless of pressure groups but as a function of universal values or principles; hence, their reasoning is guided by their own altruistic principles (Warming-Rasmussen and Windsor, 2003). Further information about the different stages can be found in Table I:

\section{[Insert Table I about here]}

Rest (1986) developed a defining issues test (DIT) to assess how people at different developmental stages make decisions when faced with moral dilemmas. Unlike Kohlberg, Rest argued that individuals could employ a combination of different types of moral reasoning simultaneously. The DIT presents individuals with certain moral dilemmas and choices that are the basis for calculating a P-score (principled moral thinking). P-score represents the participant's level of moral reasoning (see Rest, 1986). ${ }^{4}$

Several studies used DIT (or adapted context-specific versions of DIT) to study moral development among auditors and accountants (Bailey et al., 2010). Although higher levels of moral reasoning are desirable (Rest, 1986), empirical evidence indicates that auditors and accountants commonly present lower levels of moral reasoning than adults in general or other professionals (Scofield et al., 2004).

\subsection{Ethical behavioral intention}

Ethical behavioral intention is defined as giving priority to what is morally right over any other consideration (Ruiz-Palomino and Martinez-Cañas, 2011). Ethical behavioral intention was discussed in Rest's Model of Ethical Action (1986), which was one of the first and most influential models to better explain the complexity of ethical decision making (O'Fallon and Butterfield, 2005). This model suggests that moral reasoning consists of the following four components:

1. Ethical Awareness: This component addresses the identification of a moral dilemma and adopts a stakeholder approach. The individual not only has to identify that they are facing a moral dilemma but also has to make some sort of interpretation about the

\footnotetext{
${ }^{4}$ See section "4.2.2 Cognitive moral development" for a detailed explanation of the P-score.
} 
set of possible actions, the parties affected by the course of action, and how these parties would view the influence of moral dilemmas on their welfare.

2. Ethical Judgment: The second component attempts to identify the moral ideal in a specific situation. It basically looks at which course of action would be morally right. It involves the evaluation of various outcomes and choosing the most appropriate one.

3. Ethical Behavioral Intention: This component suggests that a person should actually intend to act ethically. It takes a philosophical approach to selecting from among competing value outcomes of ideals, identifying the most ethical one, and deciding whether to try to fulfil one's moral ideals.

4. Ethical Action/Behavior: In this final component, the individual actually acts ethically. The individual must have enough perseverance to overcome the obstacles and execute and implement what he/she intends to do.

These four components are not linear and do not portray that they are the virtues and traits of individuals, in defense of which Rest suggests that moral failure can occur because of deficiency in any of the components. There is a complex interaction among the four components, and it is not intended to occur in a sequential phase. This does not suggest that an individual has to follow the order strictly; in fact, the four components form a logical sequence of what it takes to behave morally. In this study, we are particularly interested in the ethical behavioral intention and not in other parts of Rest's Model of Ethical Action 1992). Several empirical studies in business ethics support the idea that ethical behavioral intention are relevant predictors of ethical action (RuizPalomino and Martinez-Cañas, 2011; Craft, 2013). When faced with moral dilemmas and making judgements, individuals' intentions can vary from a more lenient to a stricter approach (Marques and Azevedo-Pereira, 2009; Shafer and Simmons, 2011).

\section{Hypotheses development}

\subsection{Length of service: effects on moral development and ethical behavioral intentions}

There is empirical evidence showing that, in developed economies, length of service reflects higher moral reasoning among public servants. For instance, Choi (2006) found that length of service is positively associated with a post-conventional level of moral reasoning among US public servants. Therefore, public servants with longer lengths of service rely on post-conventional reasoning to resolve moral dilemmas. This finding is in 
part challenged by research that has shown that the identity and culture of certain contexts play major roles in explaining failure in public administration (Jurkiewicz, 2007).

Researchers noticed that the motives for individuals to join public administration and the interest of those individuals to remain in their jobs in certain jurisdictions are not always the ones encouraged by altruism or a prosocial motivation (Perry et al., 2010). Steward et al. (2002) suggested that length of service among Russian public administrators is negatively associated with moral reasoning. This reflects an accommodation of more experienced servants to the context. A similar negative association was also found among US private sector financial planners in investment activities (Bigel, 2000). In this context, diminished ethical orientation was attributed to a complacency effect that results from the use of shortcut rule-of-thumb heuristics that come with longer career tenure and are necessary for individuals to remain in their jobs.

The public sector is a reflection of society. Consequently, the public sector in Brazil reflects values of power distance and in-group collectivism that are characteristics of Brazilian society (Beekun et al., 2003). In this context, society accepts that strong leaders have privileges and power over others, and it is acceptable for the application of law to be uneven and seen as somewhat flexible in view of individual relationships (Husted, 2002). In such contexts, it is expected for selection and socialization to encourage cognitive reasoning based on a morality of obedience or egoism, in which individuals will morally concord with their inner group of family of friends rather than with universally accepted principles. In such contexts, public servants with longer lengths of service would have had more exposure to those values that characterize lower moral reasoning and more lenient behavior intentions. Following the above reasoning, in our sample of Brazilian public sector auditors, we expect to find length of service to be an important factor in explaining moral development and behavior intention. More specifically, we expect that public sector auditors with shorter length of service will be at higher stages of moral development and that public sector auditors' length of service will be negatively associated with stricter ethical behavioral intentions. Thus:

H1: Public sector auditors with shorter lengths of service will be at higher stages of moral development than public sector auditors with longer lengths of service.

H2. Public sector auditor length of service will be negatively associated with stricter ethical behavioral intentions. 


\subsection{Ethical ideology: effects on moral development and ethical behavioral intentions}

Most empirical research suggests that an individual's ethical ideology is an important factor in explaining differences in the level of moral reasoning (Waldman et al., 2017) and ethical behavioral intention (Nayir et al., 2018). There is evidence indicating that ethical ideologies are associated with CMD (Ishida, 2006). As previously noted, Forsyth (1980), in a seminal work on ethical ideologies, suggested that moral development would vary on an individual's position on the two dimensions of ethical ideology, namely, relativism and idealism. Relativistic individuals emphasize personal values and perspectives when facing moral dilemmas, while idealistic individuals are more inclined to believe the best outcome is achieved by following universal moral rules.

Previous literature suggests that individuals with greater idealistic orientation are more likely to sustain a higher level of integrity (Wakefield, 2008). It has been suggested that moral reasoning, ethical ideologies and how they influence each other differ among individuals from different countries of origin (Curtis et al., 2012, 2017). Although previous studies seem to indicate that more relativistic individuals vis-à-vis idealistic ones are at a lower level of moral development, there is only scarce evidence about this relationship (Craft, 2013).

According to Forsyth's (1980) ethical ideology classification, the more relativistic individuals are skeptical of absolute ethical principles and they believe that ethical behavior is contextual, whereas more idealistic individuals believe actions should bring positive consequences and that it is incorrect to follow a path that may harm others (Forsyth et al., 2008). The results drawing on Forsyth classification indicate that individuals with a more relativistic ideology could make more lenient decisions than could individuals with a more idealistic ideology. In this vein, Bobek et al. (2015) find that more lenient ethical behavioral intentions are positively associated with more relativistic US accounting professionals working in an auditing context. In the public sector, Nayir et al. (2018) also find associations between ethical ideologies and ethical behavioral intention. Their research indicates that Turkish public sector employees are more idealistic and less inclined to whistleblow externally and anonymously.

In contrast, few studies that have examined professional accountants did not find any of the ethical ideologies to be significantly different from the others in terms of their ethical judgments (e.g., Marques and Azevedo-Pereira, 2009). Douglas et al. (2001) showed that ethical ideology is a significant determinant of ethical judgments only in situations of high moral intensity. The job of a public sector auditor in Brazil is marked 
by intense moral dilemmas. It is likely that responses reflecting the level of reasoning used in resolving moral dilemmas are better observed in this context where complex and intense moral dilemmas are part of individuals' daily routines. Following the above reasoning, in our sample of Brazilian public sector auditors, we expect to find ideology to be an important factor in explaining moral development and behavior intention. More specifically, we expect that public sector auditors with a more relativistic ideology will be at lower levels of moral development and that public sector auditors' relativistic (idealistic) ideology will be positively associated with more lenient (stricter) ethical behavioral intention. Thus:

H3: Public sector auditors classified as relativistic will be at lower stages of moral development than idealistic public sector auditors.

H4: Public sector auditor relativistic (idealistic) ideology will be positively associated with more lenient (stricter) ethical behavioral intention.

\subsection{Length of service and ethical ideologies: effects on moral development}

Among all the four ideologies proposed by Forsyth (1980), absolutists are recognized as those who are more likely to be stricter when making ethical judgments (Sivadas et al., 2003). Absolutists believe that their actions should have positive consequences and that it is not acceptable to follow a path that may cause undesirable consequences to others. Accordingly, Hartikainen and Torstila (2004), in a study with finance professionals, found absolutists to be stricter when judging the actions in scenarios used to measure ethical judgements and found subjectivists to be the most lenient.

Studies show that public sector servants are committed to public, community and social service; consequently, their interest is in avoiding harm to the society they serve (Buelens and Van den Broeck, 2007). It is unclear, however, how public sector servants in highly collective developing economies with relatively weak legal systems would balance the tensions between reducing harm to society versus reducing harm to their social group when confronted with moral dilemmas. Given that empirical evidence on the effects of different ethical ideologies on ethical behavioral intentions is limited in the public sector literature in developing economies, we follow most findings in the area, and we hypothesize that public sector auditors who are classified as absolutists are stricter in their ethical behavioral intentions than are public sector auditors with other ethical ideologies. Thus: 


\section{H5: Public sector auditors classified as absolutists will be stricter in their ethical behavioral intentions than public sector auditors with other ethical ideologies.}

Additionally, empirical evidence indicates that among the four ideologies absolutist is the only one that significantly distinguishes itself from the others in terms of its relationship with CMD (Ishida, 2006). Such evidence suggests that absolutists are most likely to be at higher stages of moral development. We argue that the influence of socialization could be an important factor that transforms a decision maker's individual system of ethics, even among public servants who are classified as absolutists. A longer length of service in a highly collectivistic society moves an individual understanding of what is right based on universal values or principles to an understanding based on the morality of obedience and conformity to the expectations of the group. Thus, we hypothesize:

H6: Public sector auditors classified as absolutists with shorter lengths of service will be at higher stages of moral development than absolutist public sector auditors with longer lengths of service.

Figure 2 provides an overview of the conceptual model.

$$
\text { [Insert Figure } 2 \text { about here] }
$$

\section{Data and Methodology}

\section{1 - Instrument and participants}

Using a survey set-up, data were collected from a sample of 625 auditors who work for the Brazilian tax authority. As shown in Figure 2, this study identifies and examines the dependent variables, CMD and ethical behavioral intention, and their relationship with the independent variables, length of service and ethical ideology. As the study was examining social constructs without any manipulating variable, a survey methodology was deemed the most appropriate. The participants were not assigned to any groups, and the instrument was distributed among the participants.

In Brazil, public sector auditors [auditor fiscal] are public servants working for the Treasury Department [Secretaria da Fazenda]. They are responsible for tax and customs administration. Their daily responsibilities include combatting tax evasion, 
providing guidance to taxpayers about taxes and benefits, helping to safeguard the bank secrecy of taxpayers, and combatting currency evasion and money laundering. To qualify to this job, candidates must hold a university bachelor's degree and pass a competitive examination. The examination tests knowledge on several themes, including accounting, auditing, taxation, finance, economics, public administration and law (e.g., criminal, competition, commercial). After a probationary period, public sector auditors obtain an indefinite contract that provides them with expected lifelong job security. Periodic promotions are mostly based on the length of service. Tax collection achievements and participation on projects of the interest of the department (e.g., instructor, task force) could add to promotion decisions. Public sector auditors can exercise their activities in specific public buildings (e.g., tax offices, ports, airports and customs); however, all of them should dedicate a few hours a month for external activities such as due diligences and on-site inspections. For this purpose, they are usually assigned to subgroups that are specialized in particular areas of tax administration or business sectors. Public sector auditors are among the most specialized and better remunerated public servants in Brazil.

All of the participants in our sample were registered in a continuing professional development course. By email, they were recruited and asked to voluntarily complete an on-line instrument that included instructions, questions about the participants' background, three scenarios with context-specific moral dilemmas, questions about the specific scenarios, an ethics position questionnaire and questions about the participants' characteristics such as length of service, age, and gender. Data were collected in November 2014. The original instrument was designed in English and then translated into Portuguese. Seven academics and one linguist checked for readability, ambiguity and face validity. Following checks for the full completion of the instrument and other reliability checks as described below, a useable sample of 412 responses was available for analysis. Table II presents descriptive statistics for our sample.

\section{[Insert Table II about here]}

\subsection{Measurement of Variables}

\subsubsection{Length of service}

Following previous literature that examined organizational participants' attitudes as a function length of service (Tuggle et al. 2010) we capture length of service with a direct question that asked them about the number of years working in the current position. For 
the tests in which our objective was to understand the variable length of service, we opted to categorize it in short (length of service, $\leq 5$ ), medium (length of service, $>5$ to $\leq 15$ ) and long length of service (length of service, >15) (Gibson and Klein, 1970).

\subsubsection{Cognitive moral development}

In this research, we relied on a short-form (three scenarios) of the DIT (Rest, 1986) to measure tax auditors' CMD levels. Following Thorne (2000) and others (e.g., FrecknallHughes et al., 2017), we used context-specific scenarios instead of Rest's non-business scenarios. The aim was to allow genuine ethical responses to arise from a professional perspective. Scenario one (Capital Allowance) was borrowed from Doyle et al. (2013).

Scenarios two and three posed situations with an increasing level of moral dilemma (respectively, Ignore the Error and Whistle-Blowing). For each case, the respondents are given three tasks. Once the respondents read through the case, they first have to list their preferred course of action for that particular case (see Appendix). In the second task, they are presented with 12 statements related to the case. These 12 statements represent the six stages of moral development. Then using a 5-point scale the respondent's rate each of the 12 statements, on the basis of their importance in arriving at their preferred course of action for the individual case. The third task asks the respondents to rank the top four statements. The P-score was then calculated from these four statements. For instance, the top ranked statement would be given four points, the second ranked statement would be assigned three points and so on. As described by Turner et al (2002) and Naber and Moffett (2015) the P-score only considers moral reasoning at stages 5 and 6. Hence, if the respondent choses a statement that represents stage 4 or below, within these top four ranked statements, it would be ignored in the calculation of the P-score. Through this process, raw P-score for individual cases are first calculated. Following Rest (1986), the raw $\mathrm{P}$-score is then converted to a percentile score for each case and finally the percentiles for the three cases are added together to arrive at the P-score of the respondent (WarmingRasmussen and Windsor, 2003). Higher P-scores characterize individuals who are at higher stages of moral development.

To facilitate subsequent analysis and based on previous literature that noted there are three broad levels of moral development through which individuals progress (Rest, 1986), respondents were clustered in groups according to their overall P-score. Thus, participants were classified into one of three groups, namely, pre-conventional with a P- 
score smaller than 27, conventional with a P-score between 27 and 42, and postconventional with a P-score greater than 42 .

\subsubsection{Ethical ideologies}

Ethical ideology was measured with Forsyth's (1980) Ethical Position Questionnaire (EPQ). This questionnaire uses a 20-item scale, with ten items measuring two dimensions of the participant's ethical orientation, namely, idealism and relativism. Respondents were asked to indicate on a 7 -point Likert scale $(1=$ strongly disagree to $7=$ strongly agree) the extent to which they agreed or disagreed with each item. Factor analysis of the twenty items resulted in five factors. Examination of the scree plot and solutions showed that only factors 1 and 2 had solutions that depicted well-defined factors that accounted for the two items, with significant loadings. Consequently, the two-factor solution was adopted. Table III shows the results for the factor analysis of the ethical position questionnaire in our sample, with the respective factor loadings and communalities. The Cronbach's alpha reliability scores for the items representing idealism and relativism are 0.797 and 0.800 , respectively. The results suggest that both idealism and relativism scales have a good level of reliability. Furthermore, using the median for idealism and relativism scores (i.e., 5.30 and 3.30, respectively), respondents were classified into four categories. Thus, 90 respondents were classified as situationists (scored high in idealism and high in relativism), 102 were classified as absolutists (scored high in idealism and low in relativism), 106 were classified as subjectivists (scored low in idealism and high in relativism), and 81 were classified as exceptionists (scored low in idealism and low in relativism) $)^{5}$. Following previous researchers (Marques and Azevedo-Pereira, 2009), we excluded 33 respondents who scored at the medians for idealism and relativism because these scores were used as the cut-off points. These observations were not included in any of the statistical analyses involving any of the four distinct ethics positions as a variable.

\section{[Insert Table III about here]}

\subsubsection{Ethical behavioral intention}

Following previous researchers (e.g., Shafer, 2008; Ruiz-Palomino and Martinez-Cañas, 2011), we directly assessed the participants' ethical behavioral intention by asking them

\footnotetext{
${ }^{5}$ Scores high and low in comparison to the median.
} 
to indicate the likelihood that they would make the same decision as the decision maker described in each scenario. Scale ranges from $1=$ highly probable to $6=$ highly improbable.

\subsubsection{Control variables}

Gender and age were included as control variables. Both variables were captured by directly asking the respondents about their gender and age. Gender and age are frequently reported in ethical decision making research. Although results from previous literature for the impact of gender and age on ethical decision-making are mixed (Bailey et al., 2010), several studies show gender-specific variables and age to significantly influence moral reasoning and ethical behavioral intentions (Craft, 2013).

\subsection{Statistical Analysis}

We use multinomial logit regressions to test hypotheses H1, H3 and H6. A multinomial logit regression is appropriate data analysis technique for testing these hypotheses because it allows to predict the likelihood of the possible outcomes of dependent variables that are categorically distributed (i.e., pre-conventional, conventional, and postconventional). The general specification of the model used was as follows:

$\ln (P j / P o)=a+b j X j$

where $P j$ is the probability of an event-taking place for the $j t h$ case. The possible events are:

(1) Conventional

(2) Post-conventional

$P o$ is the probability of the default condition (reference), taken here to be the preconventional group. $X j$ is the vector of independent variables.

To test H1, which predicts the effects of lengths of service on the different stages of moral development, two dummy variables representing short $(\leq 5)$ and medium $(>5 ; \leq 15)$ lengths of service were entered in the above model as independent variables. This approach allowed us to test the likelihood that public sector auditors with different lengths of service are at different levels of CMD. To test H3, which predicts the effects of ideology on the stages of moral development, a dummy variable - more relativistic - representing 
individuals with relativism scores above the median was entered as an independent variable. This approach allow us to test the likelihood that public sector auditors with a more relativistic ideology (compared to more idealistic ones) are at different levels of CMD. Finally, to test H6, which predicts the likelihood that public sector auditors classified as absolutists with shorter lengths of service are at higher stages of moral development, we first identified and created a subsample of public sector auditors classified as absolutists. With this subsample, we ran the same models used to test H1.

We use ordinary least square (OLS) regressions to test hypotheses H2, H4 and H5. The dependent variables used for testing all these group of hypotheses - ethical behavioral intention - represent the scores resulting from the questions related to the likelihood that respondents would make the same decision as the decision maker described in each of the three scenarios (Cases 1-3) (see Appendix). H2 and H4, which predict the effects of lengths of service and ethical ideologies on ethical behavioral intentions, are tested in the same model. Length of service, relativism and idealism scores were entered as independent variables, while gender and age were entered as control variables. To test $\mathrm{H} 5$, which predicts that public sector auditors classified as absolutists will be stricter in their ethical behavioral intentions, the OLS regressions were first preceded by a MANOVA analysis. First, we calculate the ethical behavioral intention average score for each of one of the four ideological categories and via MANOVA we tested for statistical significant differences between the four categories. Second, we used OLS regressions to test H5. A dummy variable representing absolutists $(=1)$ was entered as an independent variable.

\section{Results}

First, we examined whether there was a significant difference between CMD groups (i.e., pre-conventional, conventional, post-conventional) that allowed us to treat them as separate clusters. Discriminant analysis using Wilks' Lambda test on the DIT P-score of the three levels of CMD indicated a significant difference between groups $(F=831.02$, d.f. $=2,409, \mathrm{p}<0.001)$. Table IV shows DIT P-scores per group. Although we have not hypothesized on the expected P-score, the results presented in Table IV reveal interesting findings, as the average P-score was 37.74. Out of the 412 useable observations, approximately half of the respondents were at the conventional level, and one-third were at the post-conventional level. This P-score was comparable to studies that examined accounting professionals in developed economies such as Denmark (Warming- 
Rasmussen and Windsor, 2003, P-score= 35.48), the US (Abdolmohammadi and Ariail, 2009, P-score $=38.94)$, and Ireland (Doyle et al. 2014, P-score $=33.61)$.

[Insert Table IV about here]

Table $\mathrm{V}$ displays the results for $\mathrm{H} 1$. The results show that public sector auditors with a length of service equal to or less than 5 years are more likely to be at a postconventional stage of moral development than at a pre-conventional stage of moral development when compared to public sector auditors with a length of service greater than 15 years $(\beta=1.202$, Wald $=5.060$, $p$-value $<0.05)$. Hence, $\mathrm{H} 1$ is supported.

[Insert Table V about here]

Table VI depicts results for H2. As observed in Table VI, public sector auditors' length of service is only statistically associated with ethical behavioral intention for medium length $(>5 ; \leq 15)$ in Case $2(\beta=0.395$, $p$-value $<0.05)$. Hence, H2 is not supported.

Table VII presents results for H3. The results show that public sector auditors with more relativistic ideology are less likely to be at a conventional stage of moral development than at a pre-conventional stage when compared to more idealistic public sector auditors $(\beta=-0.504$, Wald $=2.969$, $p$-value $<0.05)$. No significant results were found when testing more relativistic public sector auditors at a post-conventional stage. Hence, $\mathrm{H} 3$ is only partially supported.

Tests for H4, which predicts the effects of ethical ideologies on ethical behavioral intentions, are presented in Table VI. Results show coefficients for relativism score are negatively significant $(\beta=-0.248, \quad \mathrm{p}<0.01 ; \quad \beta=-0.121, \mathrm{p}<0.05 ; \quad \beta=-0.125, \quad \mathrm{p}<0.05)$, suggesting that relativistic public sector auditors have a more lenient ethical behavioral intention. Finally, the results reveal that 2 out of 3 coefficients for idealism score are positively significant $(\beta=0.196, p<0.05 ; \beta=0.307, p<0.01)$. Although the results are not significant for Case 3, the results mostly support the prediction that idealistic public sector auditors have stricter ethical behavioral intentions than do relativistic public sector auditors (H4). Hence, H4 is supported.

[Insert Table VI about here] 
Table VIII Panel A depicts the ethical behavioral intention average scores for the four distinct ideological categories. Absolutists present the highest score for the question related to the likelihood that they would make the same decision as the decision maker described in each of the three scenarios, which suggests that they would make stricter decisions than the other ideologies. Table VIII Panel B reports the results of a MANOVA test examining the significance of differences in the groups' ethical behavioral intention. The results indicate differences between the different groups.

[Insert Table VIII about here]

Table IX displays the results for H5. The table shows that all coefficients for the variable absolutists in the three scenarios are positive and significant $(\mathrm{p}<0.01)$, thereby supporting predictions that public sector auditors classified as absolutists make stricter ethical judgments than do public sector auditors with other ethical ideologies (H5).

[Insert Table IX about here]

Finally, tests for H6, which predicts that public sector auditors classified as absolutists with shorter lengths of service will be at higher stages of moral development, are shown in Table $\mathrm{X}$. The results do not indicate that public sector auditors classified as absolutists with shorter lengths of service ( $\leq 5$ years) will be at higher stages of moral development than are those with longer lengths of service. The results show that public sector auditors with a length of service of more than 5 years and up to 15 years (inclusive) are more likely to be at the conventional and post-conventional stages than at a preconventional stage of moral development when compared to public sector auditors with a length of service of more than 15 years $(\beta=2.002$, Wald $=4.297$, $p$-value $<0.05 ; \beta=1.639$, Wald $=2.792$, p-value $<0.05){ }^{6}$

\footnotetext{
${ }^{6} \mathrm{We}$ used a variance inflation factor (VIF) analysis to test for multicollinearity. The maximum VIFs for the independent variables in the equations shown in Tables VI and IX ranged from 2.500 to 2.669. In order to determine whether there was multicollinearity in multinomial logistic regressions reported in Tables $\mathrm{V}$, VII and $\mathrm{X}$, we transformed the dependent categorical variable $\mathrm{p}$-score into dummy variables and ran multiple ordinary linear regression. The maximum VIF for those regressions ranged from 2.287 to 2.667.
} 
[Insert Table X about here]

\section{6 - Discussion}

The empirical analysis in this study reveals several findings that enhance our understanding of how socialization and ethical ideologies affect Brazilian public sector auditors' CMD and ethical behavioral intentions. First, the results provide evidence of the relevance of context and socialization to explain moral development. Our findings suggest that there could be socialization at play within the Brazilian tax authorities and that the tax auditors regress in their ethical decision making abilities as their tenure increases. Length of service affects auditors working for the public administration in Brazil in a similar fashion, it affects accountants and auditors working for the private sector in other contexts (e.g., Abdolmohammadi and Ariail 2009). These results challenge studies on public administration that suggest that length of service positively influences public sector servants' moral development (Stensöta, 2010). Additionally, previous research has suggested that organizations may wish to focus their attention on attracting the type of employees who are most likely to engage in ethical behavior to avoid unethical behavior (McFerran et al., 2010). Our findings indicate that socialization transforms individuals, and therefore, such previous recommendations are not always enough. There must be systems in place to support individuals in continuing at higher levels of moral reasoning and in following principles with a stricter adherence to the rules. Additionally, researchers need to understand the reasons why individuals choose to work in the public sector. Perhaps individuals may perceive public sector jobs as being more socially attuned or being an idealistic employment. In many developing economies, public jobs are considered a better paying and more secure job opportunity than those in the private sector. Hence, there may be no motivation to improve one's ethical judgement, thereby resulting in the regression in their abilities to evaluate moral dilemmas as the length of their service increases.

This research also investigates ethical ideology as a major factor in explaining ethical behavioral intention and moral development. Some researchers indicate that individuals learn to generate principles of morality based on autonomy and cooperation (e.g., Kohlberg, 1984), while others suggested that different beliefs, attitudes, and values that characterize ethical ideologies might provide individuals with a framework and guidance for judgment and behavior when considering moral dilemmas (Hartikainen and Torstila, 2004). However, recent empirical evidence examining ideology among 
accounting and auditing professionals found that ethical judgments are not significantly influenced by ethical ideology, thus challenging the notion that ethical ideology is a relevant determinant of ethical judgments (Marques and Azevedo-Pereira, 2009; Shafer, 2008). Our findings indicate a direct and significant relationship between ethical ideologies and ethical behavioral intentions. The results reveal both that the more relativist a public sector auditor is, the more lenient their decision-making is and that a public sector auditor who is more idealistic is less prone to making unethical judgements. This result implies that organizations want their employees to be more idealistic than relativistic. Further division of the four ethical ideologies show that absolutists generally have higher averages for all three cases of DIT, whereas subjectivists generally have the lowest means for all three cases of DIT. Our results also indicate that absolutists have stronger and more positive ethical behavioral intentions than do individuals with other ethical ideologies. Hence, this study echoes the results found by Hartikainen and Torstila (2004).

Additionally, in this study, we examine the relationship between ethical ideology and $\mathrm{CMD}$, controlling for age and length of service. Our results indicate that public sector auditors with more relativistic ideology are more likely to be at a pre-conventional level of moral development. This result highlights the value and possibility of public sector organizations using instruments such as the DIT and EPQ to identify the level of moral development of their employees and their corresponding ethical ideology. Such a detection system would direct the organizations in providing ethical training to employees who are vulnerable to making poor ethical judgements. Such a detection system and training could be particularly useful for a country such as Brazil where tax evasion is rampant and where tax authorities have difficulties with imposing and collecting taxes (Alm and Martínez-Vázquez, 2007).

Finally, we find statistically significant results that suggest that public sector auditors classified as absolutists with a length of service between 5 and 15 years are more likely to be at higher stages of moral development when compared to public sector auditors with a longer length of service. This finding is consistent with both the socialization and moral development literature. This finding also complements our findings on length of service and the connection between ethical ideology and CMD. It shows that public sector auditors with longer lengths of service rely less on universal values or principles. Although, previous studies (Jones et al., 2003) present instances of negative relationships between length of service and moral development in the private 
sector, our findings highlight the transition in moral development of absolutist public sector auditors in Brazil after a certain length of service. The implications of this finding support the earlier arguments about a support system for public auditors. Through our study, we are able to highlight the desirable aspects of ethical decision making that should also be a part of such a support system (i.e., idealism and principled moral thinking).

\section{7 - Conclusion}

This study examines the effects of length of service and ethical ideologies on cognitive moral development and ethical behavioral intentions in Brazil. We argued that the unethical and fraudulent conduct that is well spread in the country could be partially accounted for by the weak ethical judgment of public servants in accounting and auditing positions. This study contributes to the accounting, ethics and public sector literature. First, it provides quantitative evidence of the effects of socialization and ethical ideologies on moral development among public sector auditors. This evidence adds to the limited literature on CMD and ideologies in the public sector by presenting those issues within the particular context of the public sector in Brazil, which is marked by intense moral dilemmas. Second, this study highlights a few of the idiosyncrasies within the professional culture and context of Brazilian tax authority and discusses results that could drive public policy regarding the training of Brazilian tax authorities in particular and of public sector auditors in general. Finally, as a policy implication, this research highlights the need for the public sector, in countries such as Brazil where tax evasion is rampant, to be pro-active in dealing with ethical issues and to adopt an early warning system through the constant training of public servants who are susceptible to making poor ethical judgements.

The study has a few limitations. First, socialization is studied through the lens of length of service. Despite being a strength of the study, as this approach provides a more objective measurement of socialization, it is also a limiting feature of this study. The literature has also looked at different aspects of socialization, such as knowing and learning (e.g., "know the rules, regulations and values" versus "learning the rules, regulations and values"). Future research could examine the attributes within socialization to allow for a broader understanding of the effects of social interaction in moral developing and ethical behavioral intention. Second, although results from previous research are relevant in recognizing how different ideologies could have different effects on auditors' ethical behavioral intention, the overall dearth of studies in 
the public sector limits our understanding. On the one hand, it is plausible to think that findings from the private sector could hold in the public sector, as ethical ideologies are inherent to the individuals and beyond the contextual environment. On the other hand, given the differences in motivations to join and remain in the job (including incentives), career pathways (less progression), and work conditions (including job security) between public servants and private sector workers, it is possible that ethical ideologies could have a different effect on ethical behavioral intention. Finally, the results of this study are limited to Brazil and perhaps can only be generalized to similar cultures (i.e., Latin and Ibero-American cultures). Prior research has hinted at the influence of national culture on professional judgement and ethical decision-making (Heinz et al., 2013). Hence, readers must exercise caution in generalizing the results of our study to other cultures and countries. 


\section{Appendix: Abbreviated instrument used for data collection}

\section{Case 1 from the experimental materials (Source: Doyle et al., 2013)}

Ana is a tax practitioner with an accounting firm. She is working on a capital allowance claim to benefit one of her firm's corporate clients that is in financial distress. Despite profitable trading, the client has suffered severe cash-flow problems as a result of adverse economic conditions. The capital allowances claim relates to a new factory building and will significantly reduce taxable corporate profits (and thus the tax the client has to pay). To be eligible for capital allowances, the factory has to be in use at the end of the client's financial year. Without the reduction in tax from the capital allowances, it is unlikely that the company will survive, which will result in 5,000 employees losing their jobs.

It is now a month since the client's financial year end and Ana has asked the financial controller for documentary evidence that the factory was in use at the end of the financial year. The financial controller sends her a copy of the minutes of the latest directors' board meeting. The last item on the board minutes notes that the factory became operational on the last day of the financial year. However, Ana is convinced that this was not the case as she drives past the factory every evening and it is clearly unoccupied. However, she also knows that the company will not survive if the capital allowances cannot be claimed.

Should Ana file a tax return claiming capital allowances for the financial year?

She should

I can't decide

She should not

Rate the following 12 items in terms of importance:

\begin{tabular}{|c|c|c|c|c|c|}
\hline & Great & Much & Some & Little & No \\
\hline $\begin{array}{l}1 \text { - Would it be fair to all the taxpayers who have met the legal } \\
\text { requirements to claim capital allowances if one client is permitted to } \\
\text { claim allowances without meeting the criteria? }\end{array}$ & & & & & \\
\hline $\begin{array}{l}2 \text { - What impact will the company's demise have on the accounting } \\
\text { firm Ana works for? }\end{array}$ & & & & & \\
\hline $\begin{array}{l}3 \text { - Under self-assessment, once Ana has the proper documentation } \\
\text { on file her position is covered regardless of whether the building is } \\
\text { actually 'in use'. }\end{array}$ & & & & & \\
\hline $\begin{array}{l}4 \text { - Whether Ana's notification juxtaposes immediate Revenue } \\
\text { authority cognizant of the client's actions. }\end{array}$ & & & & & \\
\hline 5 - Whether Ana and the financial controller are close friends. & & & & & \\
\hline 6 - Isn't a tax practitioner required to file an accurate tax return? & & & & & \\
\hline 7 - Aren't capital allowances a profitable alternative? & & & & & \\
\hline $\begin{array}{l}8 \text { - Which values best determine how tax practitioners should interact } \\
\text { with their clients and engage with the tax legislation? }\end{array}$ & & & & & \\
\hline $\begin{array}{l}9 \text { - Whether a tax system that includes random and meaningless } \\
\text { definitions ought to be completely abandoned. }\end{array}$ & & & & & \\
\hline
\end{tabular}




\begin{tabular}{|l|l|l|l|l|l|}
\hline $\begin{array}{l}10 \text { - Whether the saving of 5,000 jobs will bring about the best result } \\
\text { for society as a whole. }\end{array}$ & & & & \\
\hline $\begin{array}{l}11 \text { - Whether the firm's reputation will be damaged if the claim is } \\
\text { subsequently challenged. }\end{array}$ & & & & & \\
\hline $\begin{array}{l}12 \text { - Whether it is socially acceptable for management inadequacies } \\
\text { to deprive employees of their opportunity to earn a living. }\end{array}$ & & & & & \\
\hline
\end{tabular}

From the list of statements above, select the four most important:

_ Most important; __ Second most important; __ Third most important; __ Fourth most important

Assume that Ana claims capital allowance. If you were responsible for making the decision described in the scenario above, what is the probability you would make the same decision?

Highly Probable $\quad \mathrm{O} \quad \mathrm{O} \bigcirc \mathrm{O}$ ○ Highly Improbable

\section{Case 2 from the experimental materials}

Daniel works for the tax authority. Just recently he completed the auditing of A Star, which is a major local company. As Daniel's supervisor, Maria had reviewed the auditing process and made recommendations to other departments, as had one of the department colleagues. Daniel submitted his final recommendations to other departments. Several weeks later, while cleaning off his desk, Daniel found some information relating to the auditing of A Star that he had overlooked and ignored. Revision of the overlooked issue would trigger a very timeconsuming administrative procedure, while resulting in only a modest amount of additional tax being adjusted. So far nobody has noticed this oversight, and it is not likely they will. Daniel is concerned how Maria would react if he tells her. It is not the first time Daniel makes mistakes in his auditing tasks. Just recently he overheard that some colleagues of the department have indirectly criticized him for failing to catch several errors during the review process.

Should Daniel tell Maria about his error?

He should

I can't decide

He should not

Rate the following 12 items in terms of importance:

\begin{tabular}{|l|l|l|l|l|l|}
\hline & Great & Much & Some & Little & No \\
\hline $\begin{array}{l}\text { 1 - Which values best determine how tax professionals should engage } \\
\text { with their work and tax legislation? }\end{array}$ & & & & & \\
\hline $\begin{array}{l}\text { 2 - What impact will Daniel's actions have on his reputation if he } \\
\text { tells Maria about his error? }\end{array}$ & & & & & \\
\hline 3 - Is covering up an error ever a responsible act? & & & & & \\
\hline
\end{tabular}




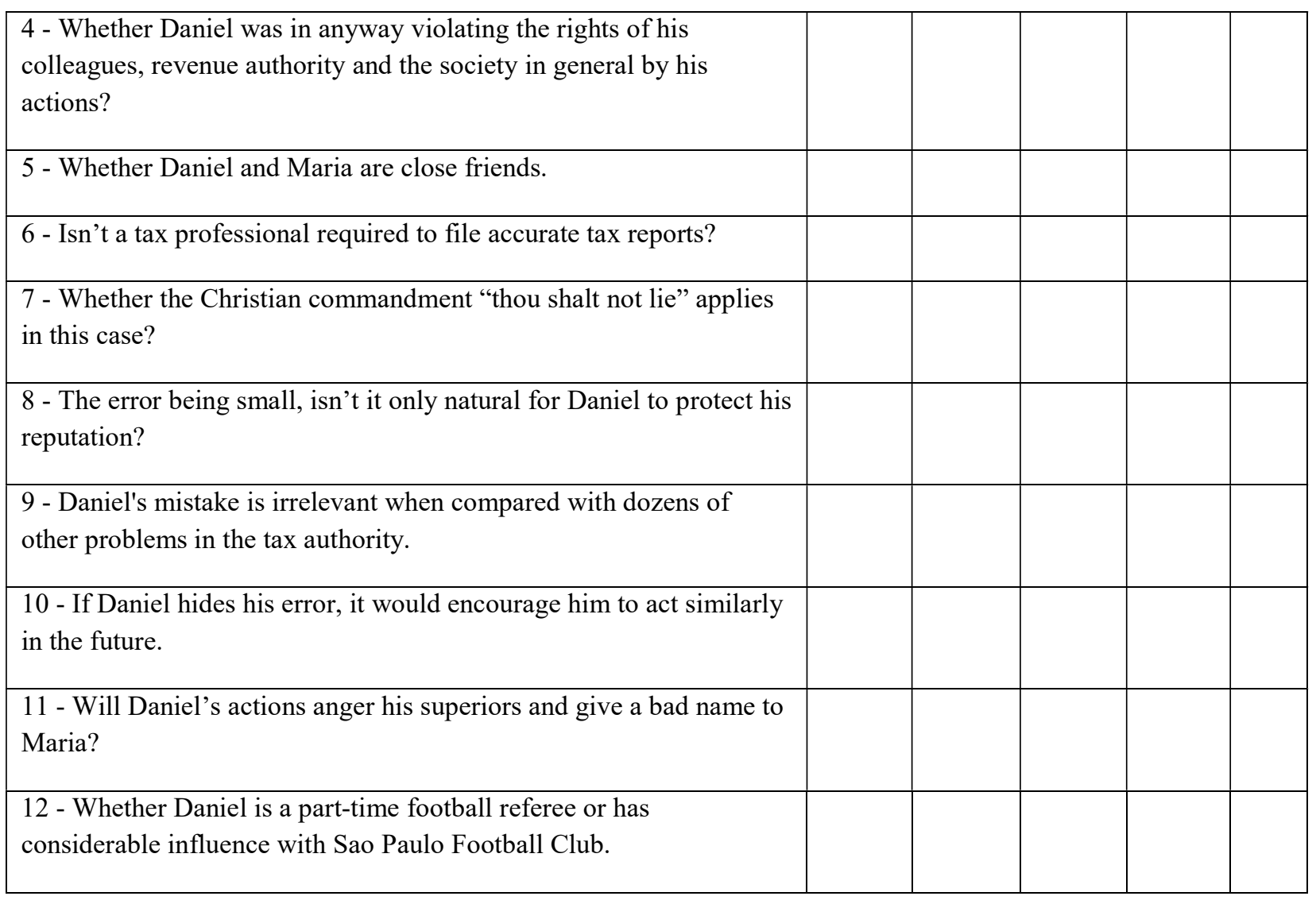

From the list of statements above, select the four most important:

Most important; Second most important; Third most important; Fourth most important

Assume that Daniel does not tell Maria about the error. If you were responsible for making the decision described in the scenario above, what is the probability you would make the same decision?
Highly Probable
○ 0
O 0
Highly Improbable

\section{Case 3 from the experimental materials}

James is a tax practitioner and works for the Revenue Department in Rio de Janeiro. James is reviewing the tax returns for a famous petroleum distribution company. Upon analysing the latest reports, James finds discrepancies in the revenue and the corresponding tax paid. James conducts an investigation and at first it appears that an error in recording revenue might be the reason behind this discrepancy. Despite James's best efforts to reconcile this discrepancy, he does not get further information from the financial controller and the owners of this company. James tries to use the documents available to him and upon deeper inspection of the Sales Tax records and the sales receipts finds that: fuel was being claimed to be destined to Mato Grosso do Sul, were the tax is lower, while the actual destination was Minas Gerais. James concludes that up to $£ 50$ million was lost in general sales tax. The paper trail also led James to discover a potential tax fraud involving a ghost-company. Furthermore, James finds multiple transactions were made with this suspicious company. James brings the matter to the attention of the director of his department, but nothing comes of it. The lack of response leads James to believe something unethical is occurring and asks the director to take action. 
The director tells James that if he discloses the information, he would be perceived as untrustworthy and unlikely to find promotion and that he may face criminal charges. The director also threatens James of fatal consequences to him and his family.

Should James report the wrong doing to higher authorities?

He should

I can't decide

He should not

Rate the following 12 items in terms of importance:

\begin{tabular}{|c|c|c|c|c|c|}
\hline & Great & Much & Some & Little & No \\
\hline $\begin{array}{l}1 \text { - Whether there are appropriate channels for reporting the } \\
\text { wrongdoing and the law and society offer adequate protection to } \\
\text { James? }\end{array}$ & & & & & \\
\hline $\begin{array}{l}2 \text { - What impact will James's actions have on his reputation if he } \\
\text { reports the wrongdoing? }\end{array}$ & & & & & \\
\hline $\begin{array}{l}3 \text { - Isn't it is the duty of any law abiding person to report a } \\
\text { wrongdoing? }\end{array}$ & & & & & \\
\hline $\begin{array}{l}4 \text {-James could expect to get into the good books of the director for } \\
\text { not reporting the wrongdoing and make quick progress in his career. }\end{array}$ & & & & & \\
\hline 5 - Whether community's laws are going to be upheld. & & & & & \\
\hline $\begin{array}{l}6 \text { - Whether James, irrespective of the threat to him and his family, } \\
\text { reporting the wrongdoing encourages others to follow suit? }\end{array}$ & & & & & \\
\hline 7 - James's actions could have a direct impact on his family. & & & & & \\
\hline 8 - Is James more responsible to the society or to his family? & & & & & \\
\hline $\begin{array}{l}9 \text { - Whether James's silence contrasts the higher authorities cognizar } \\
\text { with the tax evasion and director's collusion. }\end{array}$ & & & & & \\
\hline 10 - James is an expert at Capoeira and has recently bought a gun. & & & & & \\
\hline $\begin{array}{l}11 \text { - What values are going to be the basis for governing how society } \\
\text { acts towards whistle-blowers? }\end{array}$ & & & & & \\
\hline $\begin{array}{l}12 \text { - Whether the director and the owners of the company will be } \\
\text { allowed to hide behind a worthless law which only protects the rich } \\
\text { anyhow. }\end{array}$ & & & & & \\
\hline
\end{tabular}

From the list of statements above, select the four most important:
Most important; Second most important; Third most important; Fourth most important 
Assume that James does not report the wrongdoing. If you were responsible for making the decision described in the scenario above, what is the probability you would make the same decision?

Highly Probable $\quad \bigcirc \quad \bigcirc \quad \bigcirc \quad \bigcirc \quad \bigcirc \quad \bigcirc$ Highly Improbable

\section{Ethics Position Questionnaire (EPQ) (Forsyth, 1980)}

1. A person should make certain that his/her actions never intentionally harm another even to a small degree.

2. Risks to another should never be tolerated, irrespective of how small the risks might be.

3. The existence of potential harm to others is always wrong, irrespective of the benefits to be gained.

4. One should never psychologically or physically harm another person.

5. One should not perform an action which might in anyway threaten the dignity or welfare of another individual.

6. If an action could harm an innocent other, then it should not be done.

7. Deciding whether or not to perform an act by balancing the positive consequences of the act against the negative consequences is immoral.

8. The dignity and welfare of people should be the most important concern in any society.

9. It is never necessary to sacrifice the welfare of others.

10. Moral actions are those which closely match ideals of the most "perfect" action.

11. There are no ethical principles that are so important that they should be a part of any code of ethics.

12. What is ethical varies from one situation and society to another.

13. Moral standards should be seen as individualistic; what one person considers to be moral may be judged to be immoral by another person.

14. Different types of moralities cannot be compared as to "rightness".

15. Questions of what is ethical for everyone can never be resolved since what is moral or immoral is up to the individual.

16. Moral standards are simply personal rules which indicate how a person should behave, and not to be applied in making judgments of others.

17. Ethical considerations in interpersonal relations are so complex that individuals should be allowed to formulate their own individual codes.

18. Rigidly codifying an ethical position that prevents certain types of actions could stand in the way of better human relations and adjustment.

19. No rule concerning lying can be formulated; whether a lie is permissible or not permissible totally depends upon the situation.

20. Whether a lie is judged to be moral or immoral depends upon the circumstances surrounding the situation. 


\section{References}

Abdolmohammadi, M.J., and Ariail, D. (2009), "A test of the selection-socialization theory in moral reasoning of CPAs in industry practice", Behavioral Research in Accounting, Vol. 21 No. 2, pp. 1-12.

Afonso, J.R., Soares, J.M., and Castro, K.P. (2013), "Evaluation of the structure and performance of the Brazilian tax system: white paper on taxation in Brazil", Inter-American Development Bank, Washington, DC.

Alm, J. and Martínez-Vázquez, J. (2007), "Tax Morale and Tax Evasion in Latin America”, International Studies Program Working Paper No. 07-04, Georgia State University, Atlanta.

Bailey, C.D., Scott, I. and Thoma, S.J. (2010), "Revitalizing accounting ethics research in the neo-Kohlbergian framework: putting the DIT into perspective", Behavioral Research in Accounting, Vol. 22 No. 2, pp. 1-26.

Beekun, R.I., Stedham, Y. and Yamamura, J.H. (2003), "Business ethics in Brazil and the US: A comparative investigation", Journal of Business Ethics, Vol. 42 No. 3, pp. 267-279.

Bigel, K.S. (2000), "The ethical orientation of financial planners who are engaged in investment activities: a comparison of United States practitioners based on professionalization and compensation sources", Journal of Business Ethics, Vol. 28 No. 4, pp. 323-337.

Bobek, D.D., Hageman, A.M. and Radtke, R.R. (2015). "The effects of professional role, decision context, and gender on the ethical decision making of public accounting professionals". Behavioral Research in Accounting, Vol. 27 No. 1, pp. 55-78.

Bologna, J. and Ross, A. (2015), "Corruption and entrepreneurship: evidence from Brazilian municipalities", Public Choice, Vol. 165 No. 1, pp. 59-77.

Buelens, M. and Van den Broeck, H. (2007), "An analysis of differences in work motivation between public and private sector organizations", Public Administration Review, Vol. 67 No. 1, pp. 65-74.

Chen, C. (2012), "Sector imprinting: Exploring its impacts on managers' perceived formalized personnel rules, perceived red tape, and current job tenure", American Review of Public Administration, 42, pp. 320-340.

Craft, J.L. (2013), "A review of the empirical ethical decision-making literature: 2004-2011", Journal of Business Ethics, Vol. 117 No. 2, pp. 221-259.

Curtis, M.B., Conover, T.L. and Chui, L.C. (2012), "A cross-cultural study of the influence of country of origin, justice, power distance, and gender on ethical decision making", Journal of International Accounting Research, Vol. 11 No. 1, pp. 5-34.

Curtis, M.B., Vinson, J.M., Conover, T.L., Lucianetti, L. and Battista, V. (2017), "National culture and ethical judgment: A social contract approach to the contrast of ethical decision making by accounting professionals and students from the US and Italy", Journal of International Accounting Research, Vol. 16 No. 2, pp. 103-120.

Douglas, P.C., Davidson, R.A. and Schwartz, B.N. (2001), "The effect of organizational culture and ethical orientation on accountants' ethical judgments", Journal of Business Ethics, Vol. 34 No. 2, pp. 101-121.

Doyle, E., Frecknall-Hughes, J., and Summers, B. (2014), "Ethics in tax practice: A study of the effect of practitioner firm size", Journal of Business Ethics, Vol. 122 No. 4, pp. 623641.

Doyle, E., Hughes, J.F., and Summers, B. (2013), "An empirical analysis of the ethical reasoning of tax practitioners", Journal of Business Ethics, Vol. 114 No. 2, pp. 325-339. 
Ferreira, M., Fischer, R., Porto, J., Pilati, R. and Milfont, T. (2012), "Unraveling the Mystery of Brazilian Jeitinho: A Cultural Exploration of Social Norms", Personality and Social Psychology Bulletin, Vol. 38, pp. 331-344.

Fischer, R., Ferreira, M.C., Milfont, T. and Pilati, R. (2014), "Culture of corruption? The effects of priming corruption images in a high corruption context", Journal of CrossCultural Psychology, Vol. 45 No. 10, pp. 1594-1605.

Fleming, M., D., Romanus, R.N. and Lightner, S.M. (2009), "The effect of professional context on accounting students' moral reasoning”, Issues in Accounting Education, Vol. 24 No. 1, pp. 13-30.

Forsyth, D.R., O’Boyle, E.H.Jr., and McDaniel, M.A. (2008), "East meets West: A metaanalytic investigation of cultural variations in idealism and relativism", Journal of Business Ethics, Vol. 83 No. 4, pp. 813-833.

Forsyth, D.R. (1980), “A Taxonomy of ethical ideologies", Journal of Personality and Social Psychology, Vol. 39 No. 1, pp. 175-184.

Frecknall-Hughes, J., Moizer, P., Doyle, E. and Summers, B. (2017), “An examination of ethical influences on the work of tax practitioners", Journal of Business Ethics. Vol. 146 No. 4, pp. 729-745. doi: 10.1007/s10551-016-3037-6.

Gibson, J and Klein, S. (1970), "Employee attitudes as a function of age and length of service: A reconceptualization", Academy of Management Journal, Vol. 13 No. 4, pp. 411-425.

Hartikainen, O. and Torstila, S. (2004), "Job-Related Ethical Judgment in the Finance Profession", Journal of Applied Finance, Vol. 14 No. 1, pp. 62-76.

Heinz, P., Patel, C. and Hellmann, A. (2013), "Some theoretical and methodological suggestions for studies examining accountants' professional judgments and earnings management", Advances in accounting, Vol. 29 No. 2, pp. 299-311.

Husted, B.W. (2002), "Culture and international anti-corruption agreements in Latin America". Journal of Business Ethics, Vol. 37 No. 4, pp. 413-422.

Ishida, C. (2006), "How do scores of DIT and MJT differ? A critical assessment of the use of alternative moral development scales in studies of business ethics", Journal of Business Ethics, Vol. 67 No. 1, pp. 63-74.

Jenkins, J.G., Deis, D.R., Bedard, J.C. and Curtis, M.B. (2008), “Accounting firm culture and governance: A research synthesis", Behavioral Research in Accounting, Vol. 20 No. 1, pp. 45-74.

Jones, J., Massey, D.W. and Thorne, L., (2003), “Auditors' ethical reasoning: insights from past research and implications for the future", Journal of Accounting Literature, Vol. 22, p.45.

Jurkiewicz, C.L. (2007), "Louisiana's ethical culture and its effect on the administrative failures following Katrina", Public Administration Review, Vol. 67 No. 1, pp. 57-63.

Kjeldsen, A.M. and Jacobsen, C.B. (2012), "Public service motivation and employment sector: attraction or socialization?", Journal of Public Administration Research and Theory, Vol. 23 No. 4, pp. 899-926.

Kohlberg, L. (1984), Essays in Development. Volume II: The psychology of moral development: the nature and validity of moral stages, 272.

Kohlberg, L. (1969), "Stage and sequence: the cognitive-developmental approach to socialization", in Goslin, D.A. (Ed.), The Handbook of Socialization Theory and Research, Rand McNally, Chicago, pp. 347-480.

Lieberman, E. (2001), "National political community and the politics of income taxation in Brazil and South Africa in the 20th century", Politics and Society, Vol. 29 No. 4, pp. 515555.

Choi, D. L. (2006), "Moral reasoning in public service: Individual, organizational, and societal determinants". International Review of Public Administration, Vol. 11 No. 1, pp. 35-45. 
Marques, P.A. and Azevedo-Pereira, J. (2009), "Ethical ideology and ethical judgments in the Portuguese accounting profession", Journal of Business Ethics, Vol. 86 No. 2, pp. 227-242.

Maesschalck, J. (2004), "The impact of new public management reforms on public servants' ethics: Towards a theory". Public administration, Vol. 82 No. 2, pp.465-489.

McFerran, B., Aquino, K. and Duffy, M. (2010), "How personality and moral identity relate to individuals' ethical ideology". Business Ethics Quarterly, Vol. 20 No. 1, pp. 35-56.

Naber, A. M. and Moffett, R. G III. (2017), "Follower moral reasoning influences perceptions of transformational leadership behavior". Journal of Applied Social Psychology, Vol. 47, pp. 99-112. doi: 10.1111/jasp.12427

Nayır, D.Z., Rehg, M.T. and Asa, Y. (2018), "Influence of ethical position on whistleblowing behaviour: do preferred channels in private and public sectors differ?" Journal of Business Ethics, Vol. 149 No. 1, pp. 147-167.

OECD (2011), "Public sector integrity in Brazil. Case study 1", Secretariat of Federal Revenue, Federal Ministry of Finance", available at: http://www.oecd.org/gov/ethics/49019867.pdf.

O'Fallon, M.J. and Butterfield, K.D. (2005), "A review of the empirical ethical decisionmaking literature: 1996-2003”, Journal of Business Ethics, 59(4), pp.375-413.

Pandey, S.K., Davis, R.S. Pandey, S. and Peng, S. (2016), "Transformational Leadership and the Use of Normative Public Values: Can Employees Be Inspired to Serve Larger Public Purposes?", Public Administration, Vol. 94 No. 1, pp. 204-222.

Perry, J.L., Hondeghem, A., and Wise, L.R. (2010), "Revisiting the motivational bases of public service: twenty years of research and an agenda for the future", Public Administration Review, Vol. 70 No. 5, pp. 681-690.

Ponemon, L.A., (1990), "Ethical judgments in accounting: A cognitive-developmental perspective", Critical Perspectives on Accounting, Vol. 1 No. 2, pp. 191-215.

Ponemon, L.A., (1992), "Auditor underreporting of time and moral reasoning: An experimental lab study", Contemporary Accounting Research, Vol. 9 No. 1, pp. 171-189.

Rest, J. R. (1979), Development in Judging Moral Issues (University of Minnesota, Minneapolis, MN).

Rest, J. (1986), DIT Manual: manual for the Defining Issues Test, 3rd Edition, University of Minnesota Centre for the Study of Ethical Development, Minneapolis, MN.

Ruiz-Palomino, P. and Martinez-Cañas, R. (2011), "Supervisor role modeling, ethics-related organizational policies, and employee ethical intention: The moderating impact of moral ideology", Journal of Business Ethics, Vol. 102 No. 4, pp. 653-668.

Scofield, S.B., Phillips, T.J. and Bailey, C.D. (2004), "An empirical reanalysis of the selectionsocialization hypothesis: A research note", Accounting, Organizations and Society, Vol. 29 No. 5-6, pp. 543-563.

Shafer, W.E. (2008), "Ethical climate in Chinese CPA firms", Accounting, Organizations and Society, Vol. 33 No. 7-8, pp. 825-835.

Shafer, W.E. and Simmons, R.S. (2011), "Effects of organizational ethical culture on the ethical decisions of tax practitioners in mainland China", Accounting, Auditing \& Accountability Journal, Vol. 24 No. 5, pp. 647-668. doi:10.1108/09513571111139139.

Sierra Molina, G. and Orta Pérez, M. (2005), "La experiencia y el comportamiento ético de los auditores: Un estudio empírico". Spanish Journal of Finance and Accounting/Revista Española De Financiación Y Contabilidad, Vol. 34 No. 126, pp. 731-754.

SINPROFAZ (Sindicato Nacional dos Procuradores da Fazenda Nacional) (2015), "Sonegação no Brasil-Uma Estimativa do Desvio da Arrecadação do Exercício de 2014”, Brasilia.

Sivadas, E., Kleiser, S. B., Kellaris, J., and Dahlstrom, R. (2003), Moral philosophy, ethical evaluations, and sales manager hiring intentions. Journal of Personal Selling \& Sales Management, Vol. 23 No. 1, pp. 7-21. 
Stensöta, H. O. (2010), "The Conditions of Care: Reframing the Debate about Public Sector Ethics", Public Administration Review, March/April, pp. 295-303.

Stewart, D.W., Sprinthall, N.A. and Kem, J.D., (2002), "Moral reasoning in the context of reform: A study of Russian officials", Public Administration Review, Vol. 62 No. 3, pp. 282-297.

Thorne, L. (2000), “The development of two measures to assess accountants' prescriptive and deliberative moral reasoning", Behavioral Research in Accounting, Vol. 12, pp. 139-169.

Transparency International (2017). "Transparency International CPI". Available at: https://www.transparency.org/news/feature/corruption_perceptions_index 2017 (accessed 25th September 2018).

Tuggle, C.S., Schnatterly, K. and Johnson, R.A. (2010), "Attention patterns in the boardroom: How board composition and processes affect discussion of entrepreneurial issues", Academy of Management Journal, Vol. 53, pp. 550-571.

Turner, N., Barling, J., Epitropaki, O., Butcher, V., and Milner, C. (2002), "Transformational leadership and moral reasoning", Journal of Applied Psychology, Vol. 87, pp. 304-311.

Uysal, O. O. (2010), "Business ethics research with an accounting focus: A bibliometric analysis from 1988 to 2007”, Journal of Business Ethics, Vol. 93 No. 1, pp. 137-160. doi:10.1007/s10551-009-0187-9

Vandenabeele, W. (2008), "Government calling: public service motivation as an element in selecting government as an employer of choice”, Public administration, Vol. 86 No. 4, pp. 1089-1105.

Waldman, D., Wang, D., Hannah, S. and Balthazard, P. (2016), "A neurological and ideological perspective of ethical leadership", Academy of Management Journal, Vol. 60 No. 4, pp. 1285-1306.

Warming-Rasmussen, B. and Windsor, C.A. (2003), "Danish evidence of auditors' Level of Moral Reasoning and Predisposition to Provide Fair Judgements", Journal of Business Ethics, Vol. 47 No. 2, pp. 77-87. doi:10.1023/A:1026044615768. 
Table I: Stages in Cognitive Moral Development

\begin{tabular}{ll}
\hline Stage $^{\mathbf{a}}$ & \multicolumn{1}{c}{ Concept } \\
\hline Stage 1 & Punishment and obedience orientation \\
Stage 2 & Naive instrumental hedonism \\
Stage 3 & Good-boy or good-girl morality of maintaining good relations, approval of others \\
Stage 4 & Authority of maintaining morality \\
Stage 5 & Morality of contract, of individual rights, and of democratically accepted law \\
Stage 6 & Morality of individual principles of conscience \\
\hline
\end{tabular}

${ }^{a}$ Adapted from (Rest, 1979).

Table II. Respondents: Descriptive statistics [mean (SD)]

\begin{tabular}{|l|l|}
\hline Sample & $\mathrm{n}=412$ \\
\hline Female & $\mathrm{n}=74$ \\
\hline Male & $\mathrm{n}=338$ \\
\hline Length of service & $16.88(10.63)$ \\
\hline Age & $47.11(11.54)$ \\
\hline
\end{tabular}

Table III. Factor analysis of ethics position questionnaire from studied sample

\begin{tabular}{lccc}
\hline Items & Idealism & Relativism & $\mathrm{h}^{2}$ \\
\hline EPQ 1 & $\mathbf{0 . 7 1 9}$ & 0.275 & 0.681 \\
EPQ 2 & $\mathbf{0 . 6 5 8}$ & 0.295 & 0.587 \\
EPQ 3 & $\mathbf{0 . 6 0 5}$ & 0.266 & 0.558 \\
EPQ 4 & $\mathbf{0 . 8 0 8}$ & 0.262 & 0.757 \\
EPQ 5 & $\mathbf{0 . 6 8 7}$ & 0.306 & 0.619 \\
EPQ 6 & $\mathbf{0 . 5 6 8}$ & 0.294 & 0.467 \\
EPQ 7 & 0.185 & -0.028 & 0.561 \\
EPQ 8 & $\mathbf{0 . 5 3 9}$ & 0.230 & 0.505 \\
EPQ 9 & 0.394 & 0.230 & 0.569 \\
EPQ 10 & 0.483 & -0.061 & 0.603 \\
EPQ 11 & -0.067 & 0.397 & 0.518 \\
EPQ 12 & -0.262 & $\mathbf{0 . 5 8 6}$ & 0.549 \\
EPQ 13 & -0.308 & $\mathbf{0 . 6 8 5}$ & 0.640 \\
EPQ 14 & -0.194 & $\mathbf{0 . 5 6 7}$ & 0.472 \\
EPQ 15 & -0.264 & $\mathbf{0 . 7 4 1}$ & 0.685 \\
EPQ 16 & -0.217 & $\mathbf{0 . 6 5 5}$ & 0.631 \\
EPQ 17 & -0.321 & $\mathbf{0 . 5 1 9}$ & 0.507 \\
EPQ 18 & 0.099 & 0.122 & 0.345 \\
EPQ 19 & -0.217 & $\mathbf{0 . 6 1 4}$ & 0.646 \\
EPQ 20 & -0.336 & $\mathbf{0 . 5 8 1}$ & 0.668 \\
Factor Eigenvalue & 4.072 & 3.861 & \\
\hline
\end{tabular}

Factor pattern loadings greater than 0.50 appear in bold.

Percent of variance explained $=39.67 \%$. 
Table IV. DIT P-scores per Group [mean (SD)]

\begin{tabular}{lcccc}
\hline & Average & $\begin{array}{c}\text { Pre-conventional } \\
\text { or Low DIT } \\
\text { Group }\end{array}$ & $\begin{array}{c}\text { Conventional or } \\
\text { Mid DIT Group }\end{array}$ & $\begin{array}{c}\text { Post-conventional } \\
\text { or High DIT } \\
\text { Group }\end{array}$ \\
\hline Cases 1-3 & 37.74 & 22.73 & 35.52 & 49.58 \\
combined & $(10.68)$ & $(4.52)$ & $(3.79)$ & $(5.99)$ \\
& $\mathrm{n}=412$ & $\mathrm{n}=78$ & $\mathrm{n}=198$ & $\mathrm{n}=136$ \\
\hline
\end{tabular}

Table V. Multinomial logit for public sector auditors' stage of cognitive moral development

\begin{tabular}{|c|c|c|c|c|}
\hline \multirow[t]{2}{*}{ Dependent variable } & \multicolumn{2}{|c|}{ Conventional } & \multicolumn{2}{|c|}{ Post-Conventional } \\
\hline & Coef. & Wald & Coef. & Wald \\
\hline Length of service $(\leq 5)$ & 0.615 & 1.451 & 1.202 & $5.060 *$ \\
\hline Length of service $(>5 ; \leq 15)$ & 0.398 & 0.886 & 0.587 & 1.689 \\
\hline Length of service $(>15)$ & - & - & - & - \\
\hline Gender & -0.074 & 0.043 & 0.146 & 0.157 \\
\hline Age & 0.048 & $6.555^{* *}$ & 0.040 & $4.184 *$ \\
\hline Constant & -1.508 & 2.176 & -1.768 & 2.619 \\
\hline Observations & 412 & & 412 & \\
\hline Log-likelihood & 461.09 & & 461.09 & \\
\hline Nagelkerke & 0.042 & & 0.042 & \\
\hline
\end{tabular}

Reference group: Pre-Conventional. **Statistically significant at the 0.01 level. *Statistically significant at the 0.05 level. 
Table VI: Ethical behavioral intention regression models in context-specific scenarios

\begin{tabular}{lllllll}
\hline \multicolumn{1}{c}{ Independent variables } & \multicolumn{2}{c}{ Case 1 } & \multicolumn{2}{c}{ Case 2 } & \multicolumn{2}{c}{ Case 3 } \\
& Coeff. & t-Stat & \multicolumn{1}{c}{ Coeff. } & t-Stat & \multicolumn{1}{c}{ Coeff. } & t-Stat \\
\hline Length of service $(\leq 5)$ & 0.061 & 0.195 & 0.413 & 1.467 & 0.103 & 0.352 \\
Length of service $(>5 ; \leq 15)$ & 0.262 & 1.010 & $0.395^{*}$ & 1.683 & -0.050 & -0.203 \\
Length of service $(>15)$ & - & - & - & - & - & - \\
Relativism score & $-0.248^{* *}$ & -3.380 & $-0.121^{*}$ & -1.821 & $-0.125^{*}$ & -1.804 \\
Idealism score & $0.196^{*}$ & 2.227 & $0.307^{* *}$ & 3.858 & 0.119 & 1.434 \\
Gender & -0.034 & -0.157 & 0.222 & 1.120 & -0.178 & -0.861 \\
Age & -0.008 & -0.696 & 0.003 & 0.323 & 0.024 & $2.212^{*}$ \\
Constant & $4.728^{* *}$ & 6.158 & $3.398^{* *}$ & 4.893 & $3.416^{* *}$ & 4.712 \\
$\mathrm{R}^{2}$ & 0.046 & & 0.053 & & 0.050 & \\
F-Statistic & $3.219^{* *}$ & & $3.751^{* *}$ & & $3.557^{* *}$ & \\
Max_VIF & 2.500 & & 2.500 & & 2.500 & \\
\hline
\end{tabular}

Ordinary Least Square: Dependent variable $=$ Agreement with the judgment made on the dilemmas. **Statistically significant at the 0.01 level. *Statistically significant at the 0.05 level. (one-tailed for hypothesized links, two-tailed otherwise)

Table VII. Multinomial logit for public sector auditors' stage of cognitive moral development and ideology

\begin{tabular}{lllll}
\hline Dependent variable & \multicolumn{2}{c}{ Conventional } & \multicolumn{2}{c}{ Post-Conventional } \\
\hline & Coef. & Wald & Coef. & Wald \\
More relativistic & -0.504 & $2.969^{*}$ & -0.214 & 0.482 \\
Length of service & -0.035 & 2.147 & -0.046 & 3.318 \\
Gender & 0.102 & 0.069 & 0.318 & 0.639 \\
Age & 0.055 & $6.066^{*}$ & 0.042 & 3.156 \\
Constant & -0.714 & 0.861 & -0.458 & 0.326 \\
Observations & 379 & & 379 & \\
Log-likelihood & 719.695 & & 719.695 & \\
Nagelkerke & 0.046 & & 0.046 &
\end{tabular}

Reference group: Pre-Conventional. **Statistically significant at the 0.01 level. *Statistically significant at the 0.05 level. "The variables "more relativistic" represents individuals with relativism scores above the median. 
Table VIII: Ethical behavioral intention average scores for distinct ideological categories and MANOVA analysis

Panel A - Ethical ideologies average score in the context-specific scenarios

\begin{tabular}{|c|c|c|c|c|}
\hline & Situationists & Subjectivists & Absolutists & Exceptionists \\
\hline Case 1 & 4.44 & 4.21 & 5.22 & 4.60 \\
\hline Case 2 & 5.07 & 4.67 & 5.41 & 4.83 \\
\hline Case 3 & 4.62 & 4.33 & 5.10 & 4.74 \\
\hline Average & 4.71 & 4.40 & 5.24 & 4.72 \\
\hline \multicolumn{5}{|c|}{ Panel B - MANOVA results } \\
\hline & Value & Approx. F & $\mathrm{p}$-value & \\
\hline Pillai's Trace & 0.072 & 3.054 & 0.001 & \\
\hline Wilks' Lambda & 0.929 & 3.096 & 0.001 & \\
\hline Hotelling's Trace & 0.760 & 3.125 & 0.001 & \\
\hline Roy's Largest Root & 0.066 & 8.200 & 0.000 & \\
\hline
\end{tabular}

Table IX: Ethical behavioral intention regression models in context-specific scenarios

\begin{tabular}{lllllll}
\hline Independent variables & \multicolumn{2}{c}{ Case 1 } & \multicolumn{2}{c}{ Case 2 } & \multicolumn{2}{c}{ Case 3 } \\
& Coeff. & t-Stat & Coeff. & t-Stat & Coeff. & t-Stat \\
\hline Absolutists & 0.852 & $4.312^{* *}$ & 0.587 & $3.291^{* *}$ & 0.457 & $2.430^{* *}$ \\
Length of service & 0.005 & 0.374 & -0.010 & -0.861 & 0.002 & 0.143 \\
Gender & -0.016 & -0.074 & 0.258 & 1.275 & -0.219 & -1.027 \\
Age & -0.015 & -1.226 & 0.004 & 0.404 & 0.024 & $2.088^{*}$ \\
Constant & 5.019 & $11.463^{* *}$ & 4.755 & $12.026^{* *}$ & 3.432 & $8.236^{* *}$ \\
$\mathrm{R}^{2}$ & 0.050 & & 0.034 & & 0.058 & \\
F-Statistic & $4.956^{* *}$ & $3.249^{*}$ & & $5.783^{* *}$ & \\
Max_VIF & 2.669 & & 2.669 & & 2.669 & \\
\hline
\end{tabular}

Ordinary Least Square: Dependent variable $=$ Agreement with the judgment made on the dilemmas. **Statistically significant at the 0.01 level. *Statistically significant at the 0.05 level. (one-tailed for hypothesized links, two-tailed otherwise)

Table X. Multinominal logit for absolutists public sector auditors' stage of cognitive moral development

\begin{tabular}{|c|c|c|c|c|}
\hline Dependent variable & \multicolumn{2}{|c|}{ Conventional } & \multicolumn{2}{|c|}{ Post-Conventional } \\
\hline & Coef. & Wald & Coef. & Wald \\
\hline Length of service $(\leq 5)$ & 0.926 & 0.603 & 1.142 & 1.057 \\
\hline Length of service $(>5 ; \leq 15)$ & 2.002 & $4.297 * *$ & 1.639 & $2.792 *$ \\
\hline Length of service $(>15)$ & - & - & - & - \\
\hline Gender & 0.876 & 0.927 & 0.719 & 0.623 \\
\hline Age & 0.119 & $8.025^{* *}$ & 0.050 & 1.366 \\
\hline Constant & -5.438 & $6.015^{*}$ & -2.389 & 1.134 \\
\hline Observations & 102 & & 102 & \\
\hline Log-likelihood & 148.877 & & 148.877 & \\
\hline Nagelkerke & 0.194 & & 0.194 & \\
\hline
\end{tabular}

Reference group: Pre-Conventional. **Statistically significant at the 0.01 level. *Statistically significant at the 0.05 level. (one-tailed for hypothesized links, two-tailed otherwise) 
Figure 1. Representation of ethical ideologies

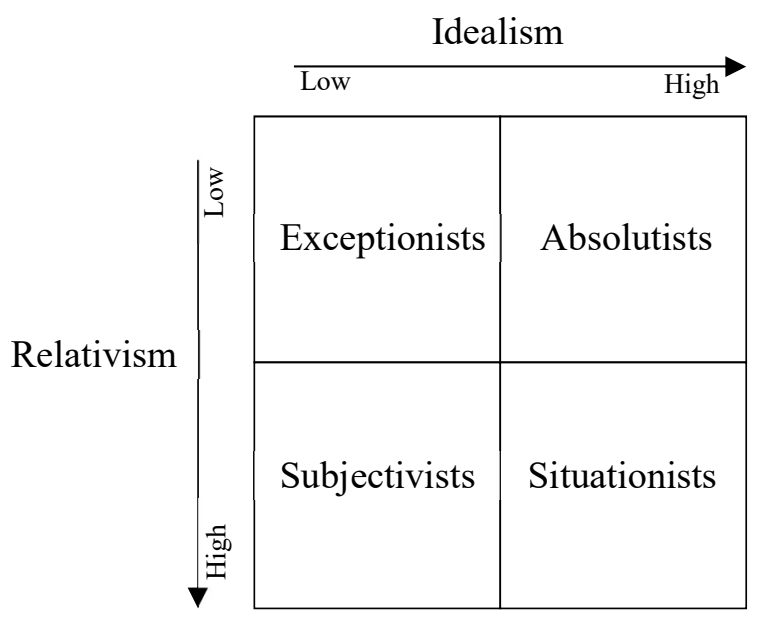

Source: Based on Forsyth (1980) 
Figure 2. Overview of the conceptual model

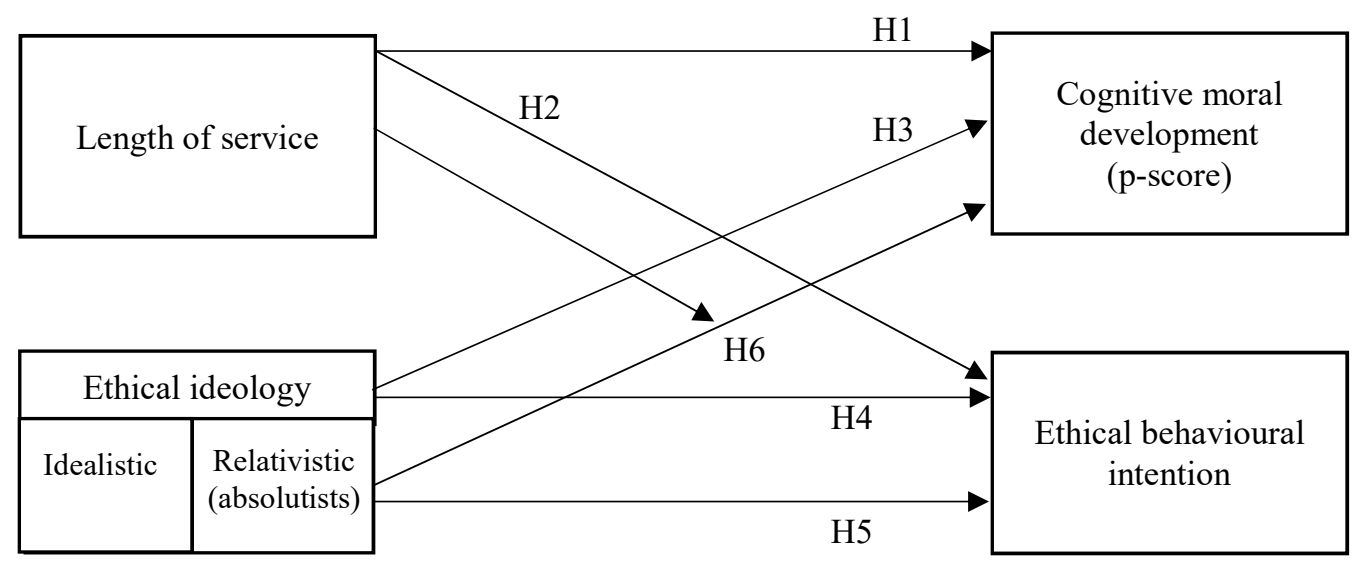

